\title{
Natural and within-farmland biodiversity enhances crop
}

\section{productivity}

Luísa Gigante Carvalheiro ${ }^{1,2^{*} \dagger}$, Ruan Veldtman ${ }^{1,3}$, Awraris Getachew Shenkute ${ }^{2}$, Gebreamlak Bezabih Tesfay ${ }^{2}$, Christian Walter Werner Pirk ${ }^{2}$, John Sydney Donaldson ${ }^{1,4}$ and Susan Wendy Nicolson $^{2}$

${ }^{1}$ Applied Biodiversity Research, South African National Biodiversity Institute, Kirstenbosch Research Centre, Private Bag X7, Claremont, 7735, South Africa. Igcarvalheiro@gmail.com, r.veldtman@sanbi.org.za, j.donaldson@sanbi.org.za

${ }^{2}$ Department of Zoology and Entomology, University of Pretoria, Pretoria 0002, South Africa. agshenkute@zoology.up.ac.za, gbtesfay@zoology.up.ac.za, cwwpirk@zoology.up.ac.za, swnicolson@zoology.up.ac.za

${ }^{3}$ Conservation Ecology and Entomology, Stellenbosch University, Private Bag X1, Matieland 7602, South Africa.

${ }^{4}$ Botany Department, University of Cape Town, Rondebosch, Cape Town

Running title - Weeds maximize nature benefits to crops 
Key words - crop pollination limitation, ecosystem services resilience, food security, Apis mellifera L., trade-offs, flower-visitation networks

Type of article - Letter

Number of words in abstract -150

Number of words in all manuscript (excl supporting information) - 6966

Number of words in main text - 4999

Number of references - 36

Number of figures - 2

Number of tables - 3

${ }^{*}$ Corresponding author: Luísa G. Carvalheiro. Applied Biodiversity Research, South African

National Biodiversity Institute, Kirstenbosch Research Centre, Private Bag X7, Claremont, 7735, South Africa. lgcarvalheiro@gmail.com

${ }^{\dagger}$ Present address: Luísa G. Carvalheiro. Institute of Integrative and Comparative Biology - Miall Building, University of Leeds, Leeds LS2 9JT, UK \& NCB-Naturalis, postbus 9517, 2300 RA, Leiden, The Netherlands. 1.g.carvalheiro@leeds.ac.uk 


\section{Abstract}

Ongoing expansion of large-scale agriculture critically threatens natural habitats and the pollination services they offer. Creating patches with high plant diversity within farmland is commonly suggested as a measure to benefit pollinators. However, farmers rarely adopt such practice, instead removing naturally occurring plants (weeds). By combining pollinator exclusion experiments with analysis of honeybee behaviour and flower-visitation webs, we found that the presence of weeds allowed pollinators to persist within sunflower fields, maximizing the benefits of the remaining patches of natural habitat to productivity of this large-scale crop. Weed diversity increased flower visitor diversity, hence ameliorating the measured negative effects of isolation from natural habitat. Although honeybees were the most abundant visitors, diversity of flower visitors enhanced honeybee movement, being the main factor influencing productivity. Conservation of natural patches combined with promoting flowering plants within crops can maximize productivity and, therefore, reduce the need for cropland expansion, contributing towards sustainable agriculture.

Key words: crop pollination limitation, ecosystem services resilience, food security, Apis mellifera L., trade-offs, flower-visitation networks, food web. 


\section{Introduction}

Pollinator-dependent crops are increasingly becoming an important component of human diets (Klein et al. 2007; Aizen et al. 2008), with their area of cultivation greatly increasing worldwide over the past 50 years (e.g. sunflowers increased by 375\%, see FAO 2010). Studies done within areas that use the same farming practices and cultivar reveal that, by isolating crop-fields from the pollinator diversity that natural habitat harbours, the expansion of agriculture is leading to negative effects on yields of pollinator dependent crops (e.g. Kremen et al. 2002; Carvalheiro et al. 2010).

Advice to farmers about maintaining and restoring pollinator communities commonly involves the creation of areas rich in plant diversity within farming landscapes (e.g. Keitt 2009; Holzschuh et al. 2010). However, such measures are seldom adopted by farmers, possibly because of costs inherent in applying such practices, such as the loss of arable land (Ghazoul 2007), or fear of competition for resources between wild plants and the crop (Weiss 1983). In fact, the opposite is more frequent, with wild occurring plants (commonly known as weeds) being exhaustively removed from extensive cultivation fields (Weiss 1983). If farmers are to adopt measures that benefit biodiversity, it is vital to assess benefits and costs of the methods suggested to enhance plant diversity within farmland. Any attempt to quantify the benefits and trade-offs of plant diversity to flower visitors can only be accomplished by considering the network of interactions that links wild plants, flower visitors and crop species as well as the potential for competition for soil resources.

Here we consider the advantages and disadvantages for conservation and agriculture of allowing ruderal plants to co-occur with a crop species. Our study crop was sunflower Helianthus annuus L., an economically important annual crop grown worldwide (FAO 2010), 
widely planted in an area of north-east South Africa where only small patchy fragments of natural habitat remain. Our first objective was to characterize the composition and structure of plant-flower visitor food webs within sunflower plantations. Honeybees are the most abundant flower visitors to sunflowers worldwide (Nderitu et al. 2008), and flower visitors are known to be affected by distance to natural habitat and by floral diversity (Kohler et al. 2008; Ricketts et al. 2008); however, the positive effects of plant diversity are only likely to occur near high quality habitats (Kohler et al. 2008). Therefore, we expected that flower visitors will be negatively affected by distance to natural habitat and distance to managed honeybee colonies; and that benefits of floral diversity within farms will be only significant near natural habitat, the composition and structure of plant-flower visitor food webs changing with increasing isolation from natural habitat. The second objective was to understand if the presence of a diverse community of flower visitors affected the foraging behavior of honeybees (Weiss 1983). Previous work revealed that non-honeybee visitors made an important indirect contribution to sunflower pollination, by altering honeybee foraging patterns (Greenleaf \& Kremen 2006). Therefore, we expected that interactions with different groups of flower visitors would enhance movement of honeybees among sunflower heads. The third objective was to understand how changes in plant-flower visitor communities affect sunflower production. The within-crop abundance of flower visitors is an important driver of the productivity of pollinator-dependent crops (Vazquez et al. 2005; Lonsdorf et al. 2009); moreover, although co-flowering plants can either compete for (Campbell \& Matlon 1985) or facilitate pollination (Lopezaraiza-Mikel et al. 2007), ruderal plants are commonly seen as detrimental to crop productivity due to competition for soil resources (Weiss 1983, farmers' personal communication). Therefore, we expected that production would be lower in the absence of flower visitors; that sunflower visitor abundance 
would be the most important driver of crop productivity; and that an increase in ruderal plant abundance would negatively affect crop productivity.

Our results show that although pollinators decline with distance to natural habitat, when ruderal plants are allowed to co-exist with pollinator-dependent crops, diverse flower visitors are able to persist in areas of cultivation fields isolated from natural vegetation, enhancing movement of honeybees among sunflowers and crop production.

\section{Materials and Methods}

This study was conducted in a commercial sunflower farming region located in Limpopo Province, South Africa $\left(27^{0} 57^{\prime} \mathrm{S}, 28^{0} 32^{\prime} \mathrm{E}\right)$, during the 2009 sunflower flowering season (March - April). The study region (approx. 54000 ha) has been used for sunflower production for several decades, rotated annually with other annuals, such as maize (Zeas mays L.) and sorghum (Sorghum sp.). Some farmers allow beekeepers to place managed honeybee colonies (average 27 colonies/site) near sunflower fields. Nine farming areas (c. $2 \mathrm{~km}$ radius; hereafter farms) with similar soil characteristics, each with 2-4 sunflower fields (50-180 ha), and several small patches of natural habitat (semi-dry savanna, $8 \%-25 \%$ cover area), at least $2 \mathrm{~km}$ away from each other, were selected within the region. Two to seven plots $\left(4 \mathrm{x} 4 \mathrm{~m}\right.$, sunflower density of 10 plants $\left./ \mathrm{m}^{2}\right)$ were selected per farm to cover a range of distances from natural habitat and from managed honeybee colonies. Plots were at least $350 \mathrm{~m}$ away from the nearest neighboring plot and $600 \mathrm{~m}$ away from any water-body, leading to a total of 33 plots, which were planted with one of five hybrid sunflower cultivars widely used for oil production. All plots selected were subjected to 
similar management practices (see plot details in Table S1 in Supporting Information), herbicides being applied annually before sowing. Insecticides are only applied in sunflower fields once every five years, but are used regularly when the fields are planted with sorghum or maize, the last insecticide application in our study plots being at least one year before data collection. In spite of herbicide application, patches of annual ruderal plants can be found within sunflower plantations. As our study plots selection maximized homogeneity of abiotic conditions (similar soil type and proximity to water-bodies) abiotic conditions are unlikely to vary much within farms. The location of ruderal plants is more likely related to occasional failures in herbicide application. Nevertheless, spatial autocorrelation of ruderal abundance and flower diversity was tested by comparing the fit of a null model with and without spatial autocorrelation structure (linear, gaussian, exponential and spherical variograms were considered). If residuals were significantly spatially autocorrelated, models were corrected accordingly (see Zuur et al. 2009). Spatial autocorrelation was equally considered in all statistical analyses described hereafter, and all analyses were performed using the software $\mathrm{R}(\mathrm{R}$ Development Core Team 2010).

\section{Objective 1-To characterize plant-flower visitor communities within sunflower plantations}

The sunflower peak flowering season (i.e. approx. 50\% of florets of the majority of the sunflower heads are open) is short, with each plot being at the peak of flowering for a maximum of one week. Therefore, each plot was surveyed on two different days (once in the morning, 09h00-13h00, and once in the afternoon, 14h00-17h00) during the peak of flowering. To assess the abundance of ruderal plants, in each survey 16 quadrats $\left(0.25 \mathrm{~m}^{2}\right)$ were randomly placed 
throughout each plot. All plant species were identified and their vegetation cover $(\%)$ and number of floral units were registered. For most species one floral unit corresponded to one flower, but for compound species (e.g. Asteraceae) one floral unit corresponds to $1 \mathrm{~cm}^{2}$ of flowers, the minimum size needed to allow one medium-sized visitor to forage without preventing visitation in the adjacent floral unit. Sunflower flower abundance was constant throughout the plots (approx. 10 sunflower heads $/ \mathrm{m}^{2}$, with an average radius of $10 \mathrm{~cm}$ of flowering florets, leading to a total of 3142 floral units $/ \mathrm{m}^{2}$ ).

In each survey, three locations (one for each of three observers) were randomly selected within the plot and all the sunflower heads at the peak of flowering that could be reached were observed for 4 minutes, during which all insects that touched the reproductive structures of those sunflowers were recorded. For each of the other flowering plant species present in the plot, observations ( $3 \times 4$ minutes) were also done, immediately after the sunflower observations. Total observation time per plant species was 24 minutes per plot. Each flower visitor specimen was counted once and collected for later identification when no potential visitors were nearby, to avoid disturbance. If the flower visitor escaped, usually it flew further than $3 \mathrm{~m}$, so we assumed it did not return to the plot within the 4 minute observation period. All Hymenoptera, Diptera and Coleoptera specimens were separated to species or morphospecies by professional taxonomists (see Acknowledgements). All other orders were sorted by the authors. To standardize visitor abundance data, the total number of specimens observed in the plot on a given plant species was divided by the number of floral units observed of that species and then multiplied by the total number of floral units in the plot. Any interaction detected outside of the observation periods was registered as a rare event (interaction frequency $=0.01$ ). Data were used to construct plant-flower visitor food webs for each plot. 
To characterize the visitation patterns within each plot, we calculated abundance and species richness of flower visitors, and network properties, such as generality (mean number of plant species per visitor), connectance (realized number of possible links between visitors and plants), linkage density (mean number of visitor specimens recorded per link), and interaction evenness (similarity of plant-visitor linkage density). Food web properties were calculated (package bipartite) using only the plots where more than one flowering ruderal species was present (26 plots). Changes in generality and connectance would indicate variation on the trophic diversity of visitors (e.g. replacement of more specialized by more generalized visitors); while changes in linkage density and interaction evenness would indicate that the different plant-insect interactions were unequally affected by the explanatory variables. To understand how these community properties change within sunflower plantations, generalized linear mixed model (GLMM, Gaussian error distribution) selection procedure was done where all combinations of explanatory variables (distance to natural habitat, natural habitat \% cover, distance to hives, flower species richness and cultivar) and their interactions were considered (package nlme). As honeybees can have large foraging ranges (von Frisch 1967), farm was included as a random variable. The most parsimonious model was selected as that with the lowest Akaike information criterion with a second-order correction for small sample sizes, AICc (Burnham \& Anderson 2002). If necessary, data were log transformed to standardize residuals. The distance from the center of each plot to the nearest patch of natural habitat and the cover (\%) of natural habitat in each farm were measured using 2008 aerial photographs. Changes in landscape that occurred after the date of the photographs, but before the flower visitor surveys, were taken into account. 


\section{Objective 2- To understand how flower visitor diversity affects honeybee foraging behaviour}

Honeybee behavior surveys were done immediately after the flower visitation surveys in all plots where visitors other than honeybees were common (26 plots). Following the methodology described in Greenleaf and Kremen (2006), honeybees foraging on sunflower were selected and followed until another visitor landed on the same sunflower head. The pair would then be observed for a maximum of 10 minutes and the behaviour of the focal honeybee (remained or flew to another sunflower head) was registered. If a third visitor landed in the sunflower head the observation was discarded. Visitors were divided in groups according to their taxonomic order, size (small [ $<0.5 \mathrm{x}$ honeybee wingspan]; medium [0.5 >>2 $\mathrm{x}$ honeybee] or large [ $>2 \mathrm{x}$ honeybee]) and activity level (low $v s$. high). For 40 minutes, the maximum number of behavioral observations was done by three observers. Data of flower visitor groups for which we had at least 14 observations were analysed using GLMM with binomial error distribution, using type of interacting species as fixed factor and plot within farm as random variables. Models were corrected for spatial autocorrelation if necessary.

\section{Objective 3- To understand how plant-flower visitor communities affect sunflower production}

To identify the contribution of flower visitors to sunflower pollination, an exclusion experiment was set up by selecting 18 sunflower heads in each of 31 study plots; nine were left open and the remaining nine were isolated from any insect visitation by covering with a white nylon mesh bag (c. $1 \mathrm{~mm}$ mesh width) before any floret opened. Although bag characteristics minimize microclimate changes (Ball et al. 1992), to ensure standard seed development conditions, all bags were removed at the end of the flowering season. Sixty days later, when seeds had reached maturity, seed set was assessed. As sunflower are valued by farmers in terms of seed mass or oil 
content (also proportional to seed mass), seed mass (i.e. weight) was used as a measure of productivity. To standardize among sunflower heads, all achenes were removed from the sunflower heads and 100 seeds were randomly selected from each and weighted. Productivity was compared using GLMM (Gaussian error distribution) with treatment (no visitors vs. all visitors) and cultivar as fixed variables and plot within farm as random variables. To evaluate if all cultivars were equally affected by the exclusion treatment, the interaction between treatment and cultivar was also included in the analysis.

To understand which characteristics of the flower visitor community and landscape most influence, hence better predict, sunflower production, variations in seed mass of sunflower heads exposed to visitors were analysed using a model selection procedure, whereby all combinations of variables potentially influencing production and their interactions were considered: distance to natural habitat, ruderal flower species richness and abundance (\% cover), cultivar, flower visitor abundance and species richness. As only one of the plots sampled was from the cultivar Monsanto 6822, this cultivar was not included in the analysis. Moreover, as any negative effect on production via soil resource competition between the crop and ruderal plants could be buffered by a potential positive effect of flower diversity on pollinators, we also evaluated the contribution of ruderal plant abundance to the variance in seed set of sunflower heads that had been isolated from pollinators (bagged sunflowers), using GLMM with plot within farm as random variable. 


\section{Results}

\section{Objective 1-To characterize plant-flower visitor communities within sunflower plantations}

Forty-seven out of 69 flower visitor species present in sunflower plantations were foraging on sunflower heads, and were also feeding on another 21 flowering plant species found within the plots (see Table S2 and S3 for details). The most abundant visitors were honeybees, which were responsible for $84 \%$ of the visits to sunflowers.

Distance to natural habitat made a significant contribution to explaining the variance in flower visitor community models, the number of honeybees and other flower visitors visiting sunflowers dropping to $61 \%$ and $24 \%$ of their maximum at $1000 \mathrm{~m}$, respectively, and species richness dropping to $57 \%$ (Fig. 1; see equations in Table 1). Although proximity to managed honeybee colonies slightly increased the number of honeybees (see Fig. S1), overall no significant influence of this variable on flower visitors was detected (Table 1).

Ruderal plant abundance was low throughout the plots (0.1-1\% of plot floral abundance and $1-20 \%$ of cover) and neither ruderal abundance (cover \%) nor flower diversity were significantly spatially auto-correlated (Contribution of best fitted variogram to the fit of the null model of abundance: $\mathrm{L}-$ ratio $=0.01, P>0.05$; diversity: $\mathrm{L}-\mathrm{ratio}=0.22, P>0.05)$. While flowering ruderals did not significantly contribute to explaining the variance in sunflower visitor abundance, they did have a positive effect on the species richness of sunflower visitors, which was $100 \%$ higher in plots with high ruderal flower diversity (maximum number of flower species within plots was 10) than in plots with only sunflower (Table 1). The positive effect of flower diversity even ameliorated the negative effect of isolation from natural habitat: diversity of sunflower visitors in plots located at $1000 \mathrm{~m}$ from natural habitat but with 10 species of flowers 
being on average $14 \%$ higher than diversity of plots located near natural habitat but with no wild flowers (5.7 species vs. 5.0 species visiting sunflower per plot, respectively, see equation in Table 1). However, the highest values of diversity occurred when both variables were optimized (10.0 species visiting sunflower in plots near natural habitat and with 10 species of flowers). Neither coverage of natural habitat within visitors foraging range nor cultivar significantly contributed to explain variance of flower visitor abundance or species richness. None of the network properties (connectance, generality, linkage density, interaction evenness) varied significantly with any of the explanatory variables considered in the analysis.

\section{Objective 2- To understand how flower visitor diversity affects honeybee foraging behaviour}

Six groups of visitors were commonly found foraging in the same sunflower heads with our focal honeybees: honeybees (139 observations); maize-beettles (medium size; low activity; 22 observations); flies (medium size; high activity; 14 observations); other bees and wasps (medium size; high activity; 22 observations); butterflies (large; high activity; 43 observations); moths (large; low activity; 30 observations). Maize-beetles (Astylus atromaculatus Blanchard), were the only medium-size Coleoptera for which we got interaction observation data. Interaction with other bee species, butterflies and moths significantly enhanced honeybee movement among sunflower heads (Table 2), with almost all $(>90 \%)$ honeybees that interacted with other bee species or with butterflies and the majority $(73 \%)$ that interacted with moths moving to another sunflower head. The majority of the honeybees that interacted with another honeybee or with maize-beetles remained foraging in the same sunflower head. Also when interacting with flies, the majority of honeybees $(77 \%)$ moved, although this effect was non-significant. 


\section{Objective 3- To understand how plant-flower visitor communities affect sunflower production}

As some control and experimental plants were found damaged, our final number of sunflower heads was 266 control and 260 experimental among all plots. The exclusion experiment revealed that sunflower visitors significantly contributed to pollination, with the seed mass of sunflower heads that had been isolated from flower visitors being significantly lower than of those heads exposed to normal insect activity (Likelihood ratio $=243.5, P<0.0001$ ). The increase in the average seed mass was consistent among all cultivars (Fig. 2), although cultivars Pannar 7533 and Monsanto DK4040 were significantly less affected than the remaining cultivars (Interaction Treatment-Cultivar: Likelihood ratio $=26.2, P<0.001$ )

When analyzing variation in productivity throughout the farms, we found that seed mass declined significantly with distance to natural habitat $(\mathrm{DN})$ and increased significantly with species richness of ruderal flowers (RFR) (see model 2 in Table 3). The positive effect of ruderal flower diversity was significant at any distance from natural habitat (Interaction DN*RFR: Likelihood ratio $=0.79, P>0.05)$ and was independent of ruderal cover (Interaction RFR*Ruderal cover: Likelihood ratio $=0.14, P>0.05$ ). However, the variation in seed set was better explained by models based on flower visitor community characteristics (see model $1 \mathrm{vs}$. model 2 in Table 3). Visitor abundance and species richness are positively correlated $(\rho=0.66, S$ $=2044.0, P<0.001$ ), both having positive impacts on production when included in models separately (see models 1 and 6 in Table 3). However, production was better predicted by variation in species richness than by visitor abundance, increasing 47-74\% from low (only honeybee) to high (14 species, the maximum number of species observed per plot) flower visitor diversity plots (Fig. S2, see equations in Table 3). Distance to managed honeybee colonies had no effect on sunflower production. 
Analysis of variation of seed mass from sunflower heads that had been isolated from pollinators, and hence mostly influenced by abiotic conditions such as competition for soil resources (water and nutrients) with other plants, revealed that ruderal plant abundance (measured as the percentage of cover) did not significantly affect sunflower production (Likelihood ratio $=0.01, \mathrm{n}=260, P>0.05)$.

\section{Discussion}

The balance between perceived costs and benefits of creating flower-rich patches within-crop fields to farmers of pollinator dependent crops is still unclear, such measures being rarely implemented in the absence of governmental subsidies (Ghazoul 2007). Our results show that if farmers allow ruderal plants to co-exist with pollinator-dependent crops, diverse flower visitors are able to persist in isolated areas of cultivation areas, benefiting production. Such benefits maximize the positive effects of the remaining patches of natural habitat. As ruderal plants in our study plots do not compete with sunflower for soil resources or reduce plantation area, this practice would bring no added costs to farmers, even reducing herbicide application costs. Therefore, if extensively applied this practice could benefit both biodiversity and agriculture. We consider the implications of these results for pollinator-dependent crop production and for conservation. 


\section{Objective 1 -To characterize plant-flower visitor communities within sunflower plantations}

Consistent with previous studies (Nderitu et al. 2008; Greenleaf \& Kremen 2006), the sunflower visitor community comprised a diverse number of species, but was dominated by honeybees. Honeybees (Apis melliferae scutellata Lepeletier) are native to the region and frequently nest in indigenous vegetation within the farm (Johannsmeier 2001). The lack of a negative effect of distance from colonies suggests that the use of managed honeybees does not compensate the loss of natural habitat. It is, however, possible that the introduction of honeybees would have a greater benefit in crop fields located in areas where natural habitat has been completely transformed.

As expected (Ricketts et al. 2008), distance to natural habitat had a negative effect on sunflower visitor abundance and species richness. However, contrary to our expectations, plant diversity had a positive effect both near and far from natural habitat, the diversity of flower visitors doubling from plots with only sunflower to plots with high flower diversity. As most flower visitors have limited foraging abilities, mostly foraging in a short radius around their nesting areas (Kohler et al. 2008), and since insecticides had not been applied in the study plots for at least one year (see methods), these results suggest that the presence of ruderal plants provided islands of resources, leading to the establishment of flower visitors in the middle of the agricultural landscape. In fact, although soil is plowed before plantation, active ground nests of wild bees were twice observed by us within sunflower plots that had high ruderal abundance, and Lepidoptera and Diptera species utilise diverse larval host plants (e.g. Smith 1976) potentially using the ruderal plants as a larval resource. A systematic survey of flower visitor nests/host plants would be necessary to fully understand the effect of ruderals on location of flower visitors' larvae. Moreover, in agreement with previous studies (Carvalheiro et al. 2010), cover of 
natural habitat within the foraging range of flower visitors did not significantly affect sunflower visitation, suggesting that the presence of small fragments of natural habitat (minimum in our study was $8 \%$ cover within $2 \mathrm{~km}$ radius) were enough to sustain crop flower visitors.

The lack of variation of network descriptors suggests that ruderal plant diversity was sufficient to maintain the visitation patterns along a gradient of distance to natural habitat. These results agree with the hypothesis that weak interactions can confer stability on a community (Neutel et al. 2007; Banasek-Ritcher et al. 2009), dampening oscillations in structure and composition of the flower visitor community. Rare interactions may be crucial to compensate the low content in important nutrients that can result from a pure diet on an Asteraceae species (e.g. sunflower) (Muller \& Kuhlmann 2008). Preserving flower visitor communities holistically and maintaining species involved in weak interactions may also ensure the ability to adapt to environmental changes (Lopezaraiza-Mikel et al. 2007), and therefore increase the resilience of pollination services. These findings highlight the importance of maintaining alternative plant species within crop fields. Nonetheless, abundance of visitors declined with distance to natural habitat, possibly because areas with permanent native vegetation ensure flower resources not only throughout the crop flowering season but throughout the year, also providing nesting sites (Tuell et al. 2008). Therefore, the benefits brought by the presence of wild plant species within crop fields will be maximized only if reservoirs of flower visitor diversity (i.e. natural habitat) are close by.

\section{Objective 2- To understand how flower visitor diversity affects honeybee foraging behaviour}

In agreement with Greenleaf and Kremen (2006), our results show that interactions with nonhoneybee visitors enhanced honeybee movement among sunflower heads. The weaker effect of 
the moths and maize-beetles could be related to the lower activity levels of these groups in comparison to bees, wasps and butterflies. The non-significant effect of flies is likely due to the low number of recorded interactions with this group. Although in our studied cultivars male and female flowers occur in the same sunflower head, they are located in different rings of the sunflower head and the majority of honeybees foraged in a localized region of the sunflower head (personal observation). Moreover, self-incompatibility mechanisms (Weiss 1983) limit the extent to which a given sunflower cultivar is able to self-pollinate. Therefore, it is likely that enhanced movement among sunflowers increases pollen flow, and hence pollination efficiency of honeybee individuals.

\section{Objective 3- To understand how plant-flower visitor communities affect sunflower production} Sunflower cultivars are being continuously developed for greater self-pollination ability (Weiss 1983), which would imply a lesser role for insect pollinators. However, our exclusion experiment results are consistent with previous findings (Nderitu et al. 2008), by showing that maintaining an abundant and diverse community of flower visitors within farmland is essential to maximize the production of several commercially used sunflower cultivars.

Changes in sunflower productivity were better explained by changes in the species richness of the flower visitor community than by changes in visitor abundance. Previous studies on crop pollination show similar results (Klein et al. 2003; Hoehn et al. 2008). As visitor abundance and species richness were correlated, both being affected by distance from natural habitat, it is difficult to detect statistically a combined effect of both variables, this being the most likely scenario. Experiments involving the manipulation of diversity in the flower visitor community independently of its abundance would be necessary to clearly separate the roles of diversity and 
abundance. Nevertheless, diversity of flower visitors can enhance pollination via several mechanisms (Klein et al. 2009). As non-honeybee visitors are a minority it is unlikely that the effect of diversity is due to the presence of more efficient pollinators (e.g. Changnon et al. 1993; Hoehn et al. 2008). The increase of honeybee movement between sunflower heads due to interactions with other flower visitor species is the likely cause for the positive effect of diversity on production. Pollen supplementation experiments would help clarify the importance of crosspollination for the productivity of different sunflower cultivars, and surveys where both abundance and visitation rate are assessed would help clarify the indirect role of diversity on pollinator efficiency.

Concerning the potential trade-offs of maintaining wild plants within cropland, our results show that the presence of ruderal plants did not have a negative impact on sunflower production, but instead had an indirect positive effect via the effect on flower visitor diversity. Bagged sunflower may be less resource-limited than fully pollinated. However, analysis of productivity of open sunflower heads shows that the indirect positive effect of ruderal diversity was not buffered at high ruderal abundances. The lack of competition between ruderal plants and sunflower could be related to the characteristics of the sunflower tap-root system (Weiss 1983), which may enable them to access resource nutrients in deeper soil layers that are inaccessible to the ruderal plants (see Walter 1971). However, weeds may compete with sunflower sprouts if they exceed a certain abundance level. Further studies involving fields where no herbicides are used, would be necessary to clarify the extent of such positive effects. Nevertheless, our results concur with previous studies showing that weed density (Hawes et al. 2010) and deposition of heterospecific pollen (Morales \& Traveset 2008) not always constrains crop productivity. 


\section{Implications for agriculture and conservation}

The rising demand on food supply is driving an accelerated replacement of natural habitat by cropland, seriously compromising sustainable development. To minimize agricultural expansion, measures that maximize productivity in the existing farming areas need to be considered. The results of this study indicate that allowing the natural occurrence of wild plants within crop fields ensures that resources for flower visitors are restored to some extent, without the loss of arable land. Such practice not only helps sustain pollinator diversity, but also benefits production in sunflower crop areas which are isolated from natural habitat. Moreover, in our study approximately $50 \%$ of the wild flowers were native. Enhancing native flower diversity in relation to alien species could maximize the benefits to conservation (see Potts et al. 2010). Further studies are necessary to better understand the relationship between the composition of wild plant communities and the benefits to crop flower visitation. Such relationships are likely to vary across crop species and regions of the world (Kohler et al. 2007), depending on the nesting requirements and foraging ability of the resident flower visitors (Lonsdorf et al. 2009).

As proximity to natural habitat also benefits the drivers of productivity (flower visitors), the benefits of within-field plant diversity to overall production are likely to be maximized if combined with the restoration of natural patches within fields and if pesticide application is kept to a minimum. Such restoration areas will, however, compromise cultivation areas not only for sunflowers but also for other non-pollinator dependent annual crops that are rotated with sunflower. Nonetheless, it is possible that such crops also benefit from the presence of wild vegetation via other ecosystem services such as pest control (e.g. Isaacs et al. 2009). Studies that combine pollination with pest control surveys are needed to understand the cost-benefit relations of such restoration areas over several years. 
Concluding remarks - By providing evidence of a crop yield improvement due to increased biodiversity (both insects and plants), this study contributes to the clarification of the value of biodiversity to crop production, providing an economic incentive for investment in pollinator-friendly farming practices. Even when abundance of an effective pollinator (honeybee) is maintained through the intense use of managed hives, in a region of the world where they are native and still unaffected by the major bee diseases/pests (Dietemann et al. 2009), pollinator diversity still makes an important contribution to crop pollination services. Such diversity can be enhanced by reducing herbicide application, allowing beneficial wild flowers to flourish throughout the crop fields. Ensuring the maintenance of diverse plantpollinator communities within farmlands can help maximize land productivity, benefit nature conservation and increase the resilience of pollination services to future environmental perturbations.

\section{Acknowledgements}

We thank C.D. Eardley (Hymenoptera), M.W. Mansell (Diptera), R. Stals (Coleoptera) for insect identification; Braam van Wyk for help with plant identification; C. Sonnekus, J. Joubert, H. Tamsen, D. Daling, C. van der Merwe, W. van der Walt, E.J. Rhodes, W. Dykamas and W. Groothof for information on sunflower farming and access to sunflower fields; P.B. Ngomana for field and lab assistance; J. Memmott for the food-web drawing program code; C. Seymour, J. Colville, E. Barbosa and three anonymous referees for comments on the manuscript; Ethiopian 
government (RCBP) for funding AGS and GBT; Claude Leon Foundation \& National Research Foundation for funding CWWP.

\section{References}

Aizen, M.A., Garibaldi, L.A., Cunningham, S.A \& Klein, A.M. (2008) Long-term global trends in crop yield and production reveal no current pollination shortage but increasing pollinator dependency. Curr. Biol., 18, 1-4.

Ball, S.T., Campbell, G.S. \& Konzak, C.F. (1992) Pollination bags affect wheat spike temperature. Crop Sc., 32, 1155-1159.

Burnham, K.P. \& Anderson, D.R. (2002) Model selection and multi-model inference, 2nd edn, Springer, New York.

Campbell, D.R. \& Matlon, A.F. (1985) The mechanism of competition for pollination between two forest herbs. Ecology, 66, 554-563.

Carvalheiro, L.G., Seymour, C.L., Veldtman, R. \& Nicolson, S.W. (2010) Pollination services decline with distance from natural habitat even in biodiversity rich areas. J. Appl. Ecol., 47, 810-820.

Dietemann, C., Pirk, C.W.W. \& Crewe, R. (2009) Is there a need for conservation of honeybees in Africa? Apidologie, 40, 285-295.

FAO (2010) Food and agriculture organization of the United Nations - FAOSTATS [WWW document]. URL http://faostat.fao.org 
von Frisch, K. (1967) The Dance Language and Orientation of Bees. Harvard University Press. Cambridge, Massachusetts and London.

Ghazoul, J. (2007) Challenges to the uptake of the ecosystem service rationale for conservation. Conserv. Biol., 21, 1651-1652.

Greenleaf, S.S. \& Kremen, C. (2006) Wild bees enhance honey bees' pollination of hybrid sunflower. Proc. Nat. Acad. Sci. USA, 103, 13890-13895.

Johannsmeier, M.F. (2001) Beekeeping in South Africa. ARC-Plant Protection Research Institute. Pretoria.

Hawes, C., Squire, G.R., Hallett, P.D., Watson, C.A. \& Young, M. (2010) Agric. Ecosyst. Environ., 138, 17-26.

Hoehn, P., Tscharntke, T., Tylianakis, J.M. \& Steffan-Dewenter, I. (2008) Functional group diversity of bee pollinators increases crop yield. Proc. R. Soc. B, 275, 2283-2291.

Holzschuh, A., Steffan-Dewenter, I. \& Tscharntke, T. (2010) How do landscape composition and configuration, organic farming and fallow strips affect the diversity of bees, wasps and their parasitoids? J. Anim. Ecol., 79, 491-500.

Isaacs, R., Tuell, J., Fiedler, A., Gardiner, M. \& Landis, D. (2009) Maximizing arthropod-mediated ecosystem services in agricultural landscapes: the role of native plants. Front- Ecol. Environ., 7, 196-203.

Keitt, T.H. (2009) Habitat conversion, extinction thresholds, and pollination services in agroecosystems. Ecol. Appl. 19, 1561-1573.

Klein, A.M., Steffan-Dewenter, I. \& Tscharntke, T. (2003) Fruit set of highland coffee increases with the diversity of pollinating bees. Proc. R. Soc. London Ser B, 270, 955-961. 
Klein, A.M. et al. (2007) Importance of pollinators in changing landscapes for world crops. Proc. R. Soc. London Ser B, 274, 303-313.

Klein, A.M., Mueller, C.M., Hoehn, P. \& Kremen, C. (2009) Understanding the role of species richness for crop pollination services, In: The consequences of changing biodiversity solutions and scenarios (eds. Bunker, D., Hector, A., Loreau, M., Perrings, C., .Naeem, S.). Oxford University Press, Oxford, pp 195-208.

Kremen, C., Williams, N.M. \& Thorp, R.W. (2002) Crop pollination from native bees at risk from agricultural intensification. Proc. Natl. Acad. Sci. USA, 99, 16812-16816.

Kohler, F., Verhulst, J., Knop, E., Herzog, F. \& Kleijn, D. (2007) Indirect effects of grassland extensification schemes on pollinators in two contrasting European countries. Biol. Cons., $135,302-307$.

Kohler, F., Verhulst, J., van Klink, R. \& Kleijn, D. (2008) At what spatial scale do high-quality habitats enhance the diversity of forbs and pollinators in intensively farmed landscapes? J. Appl. Ecol., 45, 753-762.

Lonsdorf, E., Kremen, C., Ricketts, T., Winfree, R., Williams, N. \& Greenleaf, S. (2009) Modelling pollination services across agricultural landscapes. Ann. Bot., 103, 1589-1600.

Lopezaraiza-Mikel, M.E., Hayes, R.B., Whalley, M.R. \& Memmott, J. (2007) The impact of an alien plant on a native plant-pollinator network: an experimental approach. Ecol. Lett. 10, $539-550$.

Morales, C.L. \& Traveset, A. (2008) Interspecific pollen transfer: magnitude, prevalence and consequences for plant fitness. Crit. Rev. Plant Sci., 27, 221- 238.

Muller, A. \& Kuhlmann, M. (2008) Pollen hosts of western palaearctic bees of the genus Colletes (Hymenoptera: Colletidae): the Asteraceae paradox. Biol. J. Linn. Soc., 95, 719-733. 
Nderitu, J., Nyamasyo, G., Kasia, M \& Oronjoe, M.L. (2008) Diversity of sunflower pollinators and their effect on seed yield in Makueni District Eastern Kenya. Span. J. Agric. Res., 6, 271-278.

Neutel, A., Heesterbeek, J.A.P. \& de Ruiter, P. C. (2007) Reconciling complexity with stability in naturally assembling food webs. Nature, 449, 599-602.

Potts, S.G., Biesmeijer, J.C., Kremen, C., Neuman, P., Schweiger, O. \& Kunin, W.E. (2010) Global pollinator declines: trends, impacts and drivers. Trends Ecol. Evol., 25, 345-353. R Development Core Team (2010) R: A Language and Environment for Statistical Computing. R Foundation for Statistical Computing, Vienna. [WWW document]. URL http://www.Rproject.org

Ricketts, T.H. et al. (2008) Landscape effects on crop pollination services: are there general patterns? Ecol. Lett., 11, 499-515.

Smith D.A.S. (1976). Phenotypic diversity, mimicry and natural-selection in African butterfly Hypolimnas misippus L. (Lepidoptera-Nymphalidae). Biol. J Lin. Soc., 8, 183-204.

Tuell, J.K., Fiedler, A.K., Landis, D. \& Isaacs, R. (2008) Visitation by wild and managed bees (Hymenoptera: Apidae) to eastern US native plants for use in conservation programs. Env. Ent., 37, 707-718.

Vázquez, D.P., Morris, W. F. \& Jordano, P. (2005) Interaction frequency as a surrogate for the total effect of animal mutualists on plants. Ecol. Lett., 8, 1088-1094.

Walter, H. (1971). Ecology of Tropical and Subtropical Vegetation. Oliver and Boyd, Edinburgh, UK. Weiss, E.A. (1983) Oilseed crops. Longman. London and New York. Zuur A.F., Ieno, E.N. Walker, N., Saveliev, A.A. \& Smith, G.M. (2009) Mixed effect models and extensions in Ecology with R. Springer, New York. 
Table 2 - Effect of intra and interspecific interactions on honeybee (HB) foraging behaviour. ns $-\mathrm{P}>0.05$.

\begin{tabular}{lllll}
\hline Interaction & $\begin{array}{l}\text { HB movement to } \\
\text { other sunflower } \\
\text { head }\end{array}$ & $\begin{array}{l}\text { Average foraging time } \\
\text { before movement (sec) }\end{array}$ & $\begin{array}{l}\text { Movement paired } \\
\text { comparison with } \\
\text { HB-HB interaction }\end{array}$ \\
\hline HB-HB & $46 \%$ & $101 \pm 105$ & z-test value & P-value \\
HB - maize-beetle & $36 \%$ & $145 \pm 70$ & -1.37 & $\mathrm{~ns}$ \\
HB - fly & $71 \%$ & $86 \pm 74$ & 1.21 & $\mathrm{~ns}$ \\
HB - Other bee & $91 \%$ & $73 \pm 43$ & 2.43 & $<0.02$ \\
HB - Butterfly & $93 \%$ & $65 \pm 69$ & 4.47 & $<0.0001$ \\
HB - Moth & $73 \%$ & $101 \pm 82$ & 3.82 & $<0.0002$ \\
\hline
\end{tabular}


Table 3. Effect of distance to natural habitat (DN), ruderal flower species richness (RFR) and ruderal plant abundance (RA), sunflower flower visitor abundance (FVA) and species richness (FVR) and cultivar (C) on sunflower seed set. Number of observations was 259 and random variables (plot within farm) groups were 31. P-values were obtained from a likelihood ratio test in which deviances with and without that term in the model were compared. n.s., $P>0.05$. As FVA and FVR are driven by DN and RFR, to compare the contributions of the different sets of variables, the seven most parsimonious models are listed according to AICc values and the equation of the best model (lowest AICc) is provided for each cultivar. No significant spatial autocorrelation of residuals was detected in the models. The symbol "-" represents a variable not included in the model. Interactions between explanatory variables did not contribute significantly to any of the models.

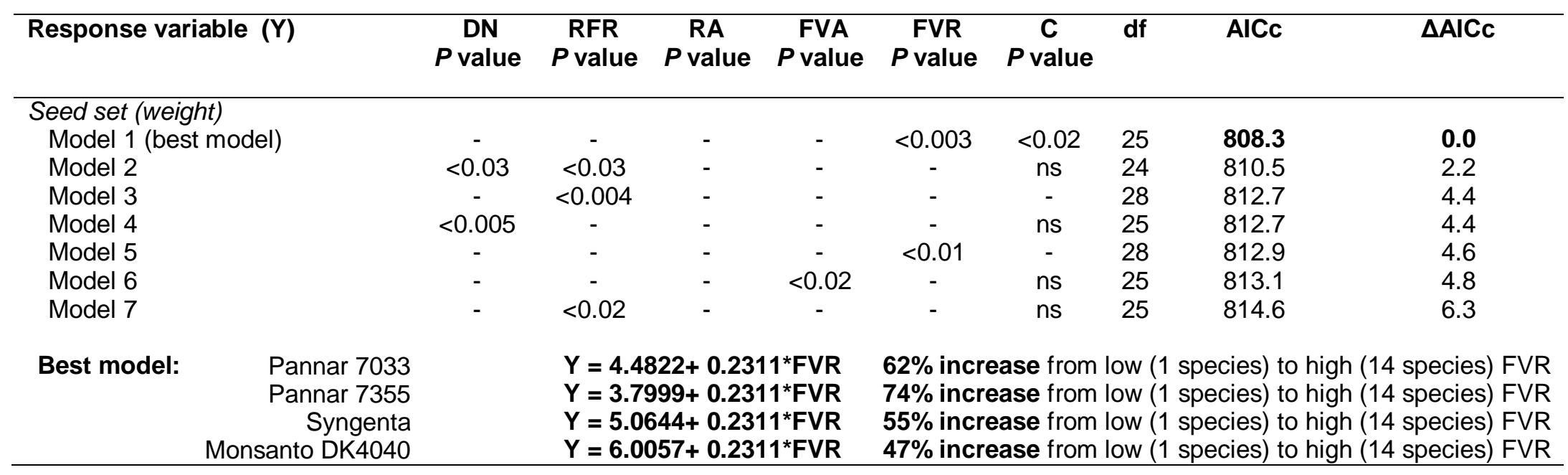




\title{
Figures
}

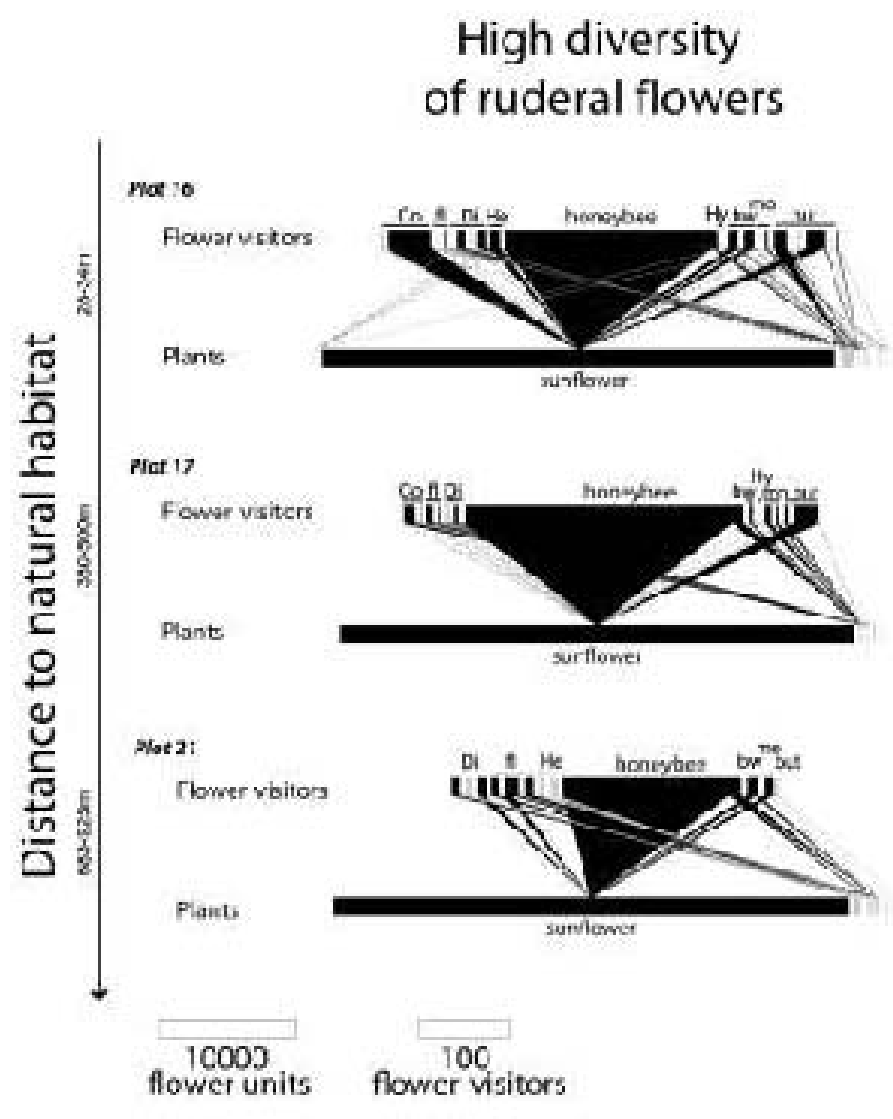

\author{
Low diversity \\ of ruderal flowers
}

Por 4

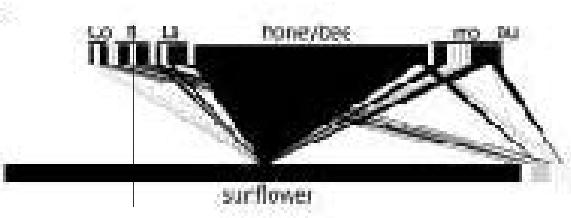

Pla!)

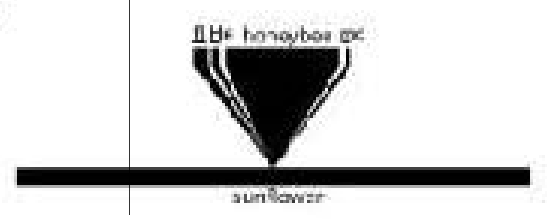

Mot 1

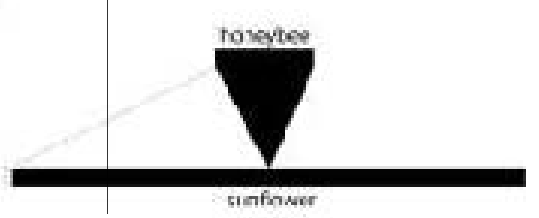

Figure 1 


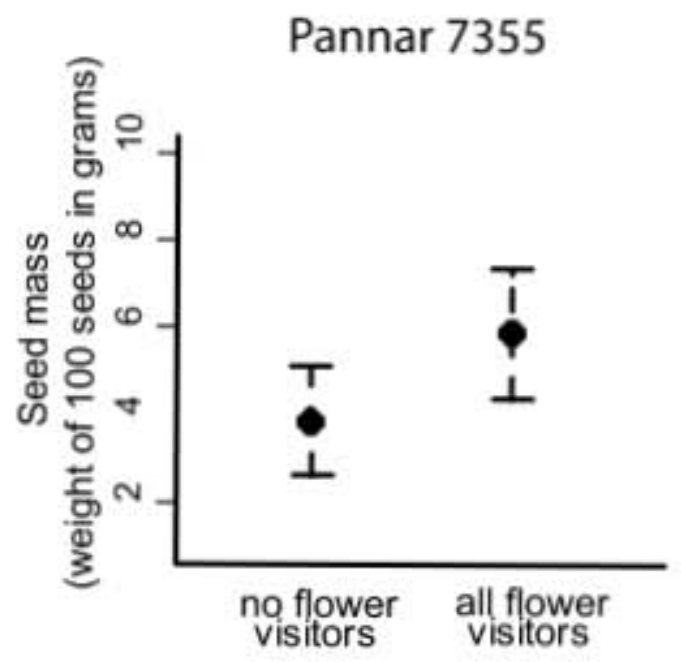

Pannar 7033
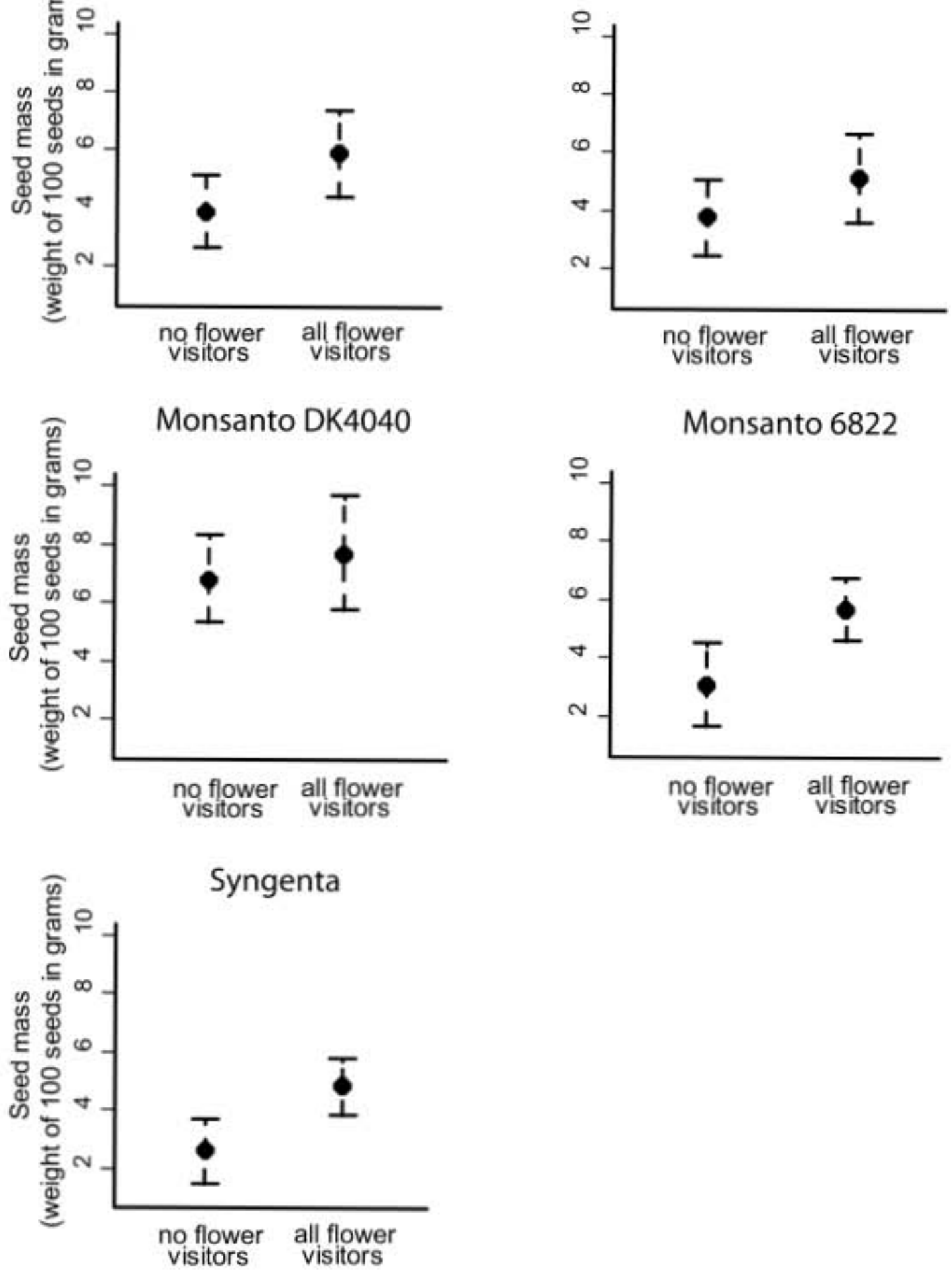

Figure 2 


\section{Figure legends}

Figure 1. Effect of distance to natural habitat and of ruderal flowering plant diversity on sunflower flower visitation webs. The six plots here presented represent two sets of plots located within the same farm ( 5 and 3, respectively) and are located far (670-2000 m) from managed honeybee colonies and near (28-34m), at medium distance (380-500m) and far (879-925m) from natural habitat. Each species of plant and insect is represented by a rectangle. The overall list of species is provided in Tables $\mathrm{S} 2$ and $\mathrm{S} 3$. The widths of the rectangles represent overall species abundance per plot per survey and the size of the lines connecting them represents the number of insects visiting each plant species. Sunflower and its flower visitors are shown in black, while other species are presented in grey. Dashed lines represent rare interactions.

Figure 1 foot note: $\mathrm{mb}$ - maize-beetle (0.5-2 x honeybee wingspan; high activity); Co - other Coleoptera, fl - flies (0.5-2 x honeybee wingspan; high activity); Di - other Diptera; He Heteroptera; bw - other bees and wasps (0.5-2 x honeybee wingspan; high activity); Hy - other Hymenoptera; mo - moths (> $2 \mathrm{x}$ honeybee wingspan; low activity); but - butterflies (> $2 \mathrm{x}$ honeybee wingspan; high activity). 
Figure 2. Mean \pm standard deviation (whiskers) sunflower seed mass in different cultivars exposed to or isolated from flower visitors. Pannar 7355, $\mathrm{n}=238$; Pannar 7033, $\mathrm{n}=188$; Monsanto 6822, $\mathrm{n}=14$; Monsanto DK4040, $\mathrm{n}=53$; Syngenta, $\mathrm{n}=33$. Number of observations was 526 and random variable (plot within farm) groups were 31. 


\section{Supporting information}

Title: Natural and within-farmland biodiversity enhances crop productivity

Authors: Carvalheiro, Luisa G.; Veldtman, Ruan; Shenkute, Awraris G.; Tesfay, Gebreamlak B.;

Pirk, Christian W.W.; Donaldson, John S.; Nicolson, Sue W.

Table S1. Summary details of the sunflower plots used in this study.

\begin{tabular}{|c|c|c|c|c|c|c|}
\hline Plot & Farm & $\begin{array}{l}\text { Distance to } \\
\text { natural habitat } \\
(\mathrm{m})\end{array}$ & $\begin{array}{c}\text { Distance to } \\
\text { managed } \\
\text { honeybees }(\mathrm{m})\end{array}$ & $\begin{array}{l}\text { Ruderal plant } \\
\text { abundance } \\
\text { (\% cover) }\end{array}$ & Cultivar & $\begin{array}{c}\text { Seed set } \\
\text { data } \\
\text { available? }\end{array}$ \\
\hline 1 & 1 & 108 & 90 & 7 & Pannar 7033 & Yes \\
\hline 2 & 1 & 515 & 500 & 5 & Pannar 7033 & Yes \\
\hline 3 & 2 & 46 & 1350 & 6 & Pannar 7033 & Yes \\
\hline 4 & 2 & 487 & 1800 & 10 & Pannar 7033 & Yes \\
\hline 5 & 3 & 28 & 1300 & 10 & Pannar 7355 & Yes \\
\hline 6 & 3 & 30 & 85 & 12 & Pannar 7355 & yes \\
\hline 7 & 3 & 380 & 970 & 20 & Pannar 7355 & yes \\
\hline 8 & 3 & 404 & 560 & 5 & Pannar 7355 & yes \\
\hline 9 & 3 & 410 & 980 & 14 & Pannar 7355 & yes \\
\hline 10 & 3 & 601 & 1100 & 12 & Pannar 7033 & yes \\
\hline 11 & 3 & 683 & 670 & 5 & Pannar 7355 & yes \\
\hline 12 & 4 & 744 & 1900 & 4 & Pannar 7355 & yes \\
\hline 13 & 4 & 781 & 70 & 7 & Syngenta & yes \\
\hline 14 & 4 & 1165 & 490 & 10 & Syngenta & yes \\
\hline 15 & 4 & 1220 & 970 & 6 & Syngenta & yes \\
\hline 16 & 5 & 34 & 2000 & 9 & Pannar 7355 & yes \\
\hline 17 & 5 & 500 & 1500 & 10 & Pannar 7355 & yes \\
\hline 18 & 5 & 540 & 1000 & 11 & Pannar 7355 & yes \\
\hline 19 & 5 & 765 & 1200 & 1 & Pannar 7355 & yes \\
\hline 20 & 5 & 780 & 540 & 12 & Pannar 7355 & yes \\
\hline 21 & 5 & 925 & 1050 & 6 & Pannar 7355 & yes \\
\hline 22 & 5 & 1000 & 100 & 6 & Pannar 7355 & yes \\
\hline 23 & 6 & 30 & 2300 & 14 & Pannar 7033 & yes \\
\hline 24 & 6 & 280 & 2200 & 20 & Pannar 7033 & yes \\
\hline 25 & 6 & 553 & 2100 & 12 & Pannar 7033 & yes \\
\hline 26 & 7 & 37 & 170 & 10 & MonsantoDK4040 & yes \\
\hline 27 & 7 & 461 & 550 & 12 & MonsantoDK4040 & yes \\
\hline 28 & 8 & 652 & 1070 & 14 & Pannar 7033 & yes \\
\hline 29 & 8 & 910 & 220 & 6 & Pannar 7033 & yes \\
\hline 30 & 8 & 923 & 1040 & 5 & Pannar 7033 & no \\
\hline
\end{tabular}




\begin{tabular}{llccccc}
\hline 31 & 8 & 933 & 520 & 13 & Pannar 7033 & yes \\
32 & 9 & 45 & 340 & 10 & Monsanto6822 & no \\
33 & 9 & 184 & 539 & 18 & Monsanto6822 & yes \\
\hline
\end{tabular}


Table S2. List of flowering plants recorded during surveys in sunflower plots. * - alien plant

\begin{tabular}{llccc}
\hline & & Total \\
Code Plant species & Plant family & $\begin{array}{c}\text { Total } \\
\text { number of } \\
\text { visitors }\end{array}$ & $\begin{array}{c}\text { number } \\
\text { of floral } \\
\text { units }\end{array}$ & $\begin{array}{c}\text { Visitors per } \\
\text { floral unit) }\end{array}$ \\
\hline 1 Flaveria bidentis (L.) Kuntze* & Asteraceae & 82 & 230 & 0.36 \\
2 Helianthus annuus L.* & Asteraceae & 5115 & 969671 & 0.01 \\
3 Schkuhria pinnata (Lam.) Kuntze ex Thell.* & Asteraceae & 22 & 2066 & 0.01 \\
4 Senecio apiifolius (DC.) Benth. \& Hook. & Asteraceae & 169 & 821 & 0.21 \\
5 Sonchus asper (L.) Hill * & Asteraceae & 0 & 2 & 0 \\
6 Tagetes minuta L. * & Asteraceae & 251 & 6853 & 0.04 \\
7 Bidens pilosa L. * & Asteraceae & 0 & 2 & 0 \\
8 Zinnia peruviana (L.) L. * & Asteraceae & 0 & 5 & 0 \\
9 Commelina erecta L. & Commelinaceae & 4 & 428 & 0.01 \\
10 Ipomoea coscinosperma (Choisy) Hochst. & Convulvulaceae & 8 & 133 & 0.06 \\
11 Fabaceae sp. & Fabaceae & 16 & 113 & 0.14 \\
12 Ocimum sp. * & Lameaceae & 47 & 617 & 0.08 \\
13 Hibiscus trionum L. * & Malvaceae & 4 & 14 & 0.29 \\
14 Euphorbiaceae sp. & Euphorbiaceae & 38 & 23 & 1.65 \\
15 Cucumis anguria L. var. longaculeatus J. H. Kirkbr. Cucurbitaceae & 2 & 9 & 0.22 \\
16 Sesamum triphyllum (Asch.)Welw. & Pedaliaceae & 5 & 32 & 0.16 \\
17 Kohautia cynanchica DC & Rubiaceae & 2 & 25 & 0.08 \\
18 Richardia brasiliensis Gomes * & Rubiaceae & 22 & 1035 & 0.02 \\
19 Cardiospermum grandiflorum Sw. & Sapindacea & 0 & 5 & 0 \\
20 Datura ferox L. & Solanaceae & 0 & 9 & 0 \\
21 Solanum retroflexum Dunal.* & Solanaceae & 0 & 16 & 0 \\
22 Tribulus terrestris L. & Zygophyllaceae & 0 & 2 & 0 \\
\hline
\end{tabular}


Table S3. List of flower visitors recorded during surveys in sunflower plots. "ni" - not identified. When it was not possible to separate specimens in morphospecies with accuracy (when specimens escaped or were damaged) specimens were grouped in morphospecies (Sarcophagidae sp., Calliophoridae sp., Lasioglossum sp. and Chalcidoidea sp.). Species that were considered for the honeybee behavioural observations are indicated in the 'Order' column: $\mathrm{mb}$ - maize-beetle (0.5-2 x honeybee wingspan; low activity); fl - flies (0.5-2 x honeybee wingspan; high activity); bw - other bees and wasps (0.5-2 x honeybee wingspan; high activity); mo - moths (> 2 x honeybee wingspan; low activity); but - butterflies ( $>2 \mathrm{x}$ honeybee wingspan; high activity). Reference specimens were kept in University of Pretoria or with the taxonomists.

\begin{tabular}{|c|c|c|c|c|c|}
\hline Code & Insect & Family & Order & $\begin{array}{c}\text { Relative } \\
\text { abundance } \\
(\%)\end{array}$ & $\begin{array}{l}\text { Importance to } \\
\text { sunflower } \\
\text { (\% of visitors) }\end{array}$ \\
\hline 1 & Decaria sp1 & Chrysomelidae & Coleoptera & 0.38 & $<0.01$ \\
\hline 2 & Monolepta citrinella Jacoby & Chrysomelidae & Coleoptera & 0.21 & 0.2 \\
\hline 3 & Coccinellidae sp1 & Coccinellidae & Coleoptera & 0.08 & - \\
\hline 4 & Baris cf. atrocoerulea (Boheman) & Curculionidae & Coleoptera & 0.1 & 0.1 \\
\hline 5 & Lathrididae sp1 & Lathrididae & Coleoptera & 0.21 & 0.2 \\
\hline 6 & Astylus atromaculatus Blanchard & Melyridae & Coleoptera (mb) & 5.23 & 5.8 \\
\hline 7 & Melyridae sp1 & Melyridae & Coleoptera & 0.17 & 0.2 \\
\hline 8 & Carpophilus sp1 & Nitidulidae & Coleoptera & 1.50 & 1.5 \\
\hline 9 & Meligethes sp1 & Nitidulidae & Coleoptera & 0.02 & - \\
\hline 10 & Lagria cf. aeneipennis Fåhraeus & Tenebrionidae & Coleoptera & 0.56 & 0.5 \\
\hline 11 & Bombyliidae sp1 & Bombyliidae & Diptera & 0.03 & - \\
\hline $\begin{array}{l}12 \\
13\end{array}$ & $\begin{array}{l}\text { Bombyliidae sp2 } \\
\text { Caliophoridae sp } \\
\text { (Chrysomya sp. \& others) }\end{array}$ & $\begin{array}{l}\text { Bombyliidae } \\
\text { Caliophoridae }\end{array}$ & $\begin{array}{l}\text { Diptera } \\
\text { Diptera (fl) }\end{array}$ & $\begin{array}{l}0.01 \\
0.47\end{array}$ & $\overline{-}$ \\
\hline 14 & Rhyncomya sp. & Caliophoridae & Diptera (fl) & 0.01 & $<0.01$ \\
\hline 15 & Conopidae sp1 & Conopidae & Diptera & 0.06 & - \\
\hline 16 & Empididae sp1 & Empididae & Diptera & 0.65 & - \\
\hline $\begin{array}{l}17 \\
18\end{array}$ & $\begin{array}{l}\text { Empididae sp2 } \\
\text { Sarcophagidae sp. } \\
\text { (2 species at least) }\end{array}$ & $\begin{array}{l}\text { Empididae } \\
\text { Sarcophagidae }\end{array}$ & $\begin{array}{l}\text { Diptera } \\
\text { Diptera (fl) }\end{array}$ & $\begin{array}{l}0.02 \\
0.77\end{array}$ & 0.4 \\
\hline 19 & Betasyrphus adliagatus Wiend. & Syrphidae & Diptera (fl) & 0.68 & 0.2 \\
\hline 20 & Eumerus obliquus Fab. & Syrphidae & Diptera & 0.48 & 0.1 \\
\hline 21 & Senaspis haemorrhoa Gerst. & Syrphidae & Diptera (fl) & 0.16 & 0.2 \\
\hline 22 & Betasyrphus sp1 & Syrphidae & Diptera (fl) & 0.33 & 0.4 \\
\hline 23 & Eristalinus taeniops (Wied) & Syrphidae & Diptera (fl) & 0.17 & 0.1 \\
\hline 24 & Ischiodon aegyptius (Wied) & Syrphidae & Diptera & 0.13 & - \\
\hline 25 & Eristalinus cf. plurivittatus (Macq ) & Syrphidae & Diptera & 0.01 & - \\
\hline 26 & Syrphidae sp1 & Syrphidae & Diptera & 0.02 & - \\
\hline 27 & Tephritidae sp & Tephritidae & Diptera & 1.37 & 0.5 \\
\hline 28 & Diptera sp1 & $\mathrm{Ni}$ & Diptera & 0.09 & - \\
\hline 29 & Diptera sp2 & ni & Diptera & 0.32 & 0.2 \\
\hline 30 & Spilostethus pandurus Scopoli & Lygaeidae & Heteroptera & 0.08 & $<0.01$ \\
\hline
\end{tabular}


$31 \quad$ Lygaeidae sp1

32 Nezara viridula $\mathrm{L}$.

33 Tingidae cf. sp1

34 Apis mellifera L.

35 Tetraloniella apicalis cf. (Friese)

36 Xylocopa inconstans Smith cf.

37 Braconidae sp1

38 Braconidae sp2

39 Chalcidoidea sp.

40 Formicidae sp1

41 Lasioglossum sp.

42 Lipotriches sp. cf

43 Systropha sp1

44 Megachile frontalis Fab. cf.

45 Campsomeris sp1

46 Belanogaster sp1

47 Vespidae sp1

48 Amata cerbera L.

49 Utetheisa pulchella L.

50 Eudalaca exul Herrich-Schäffer cf.

51 Spialia sp1

52 Hesperidae sp1

53 Borbo sp1

55 Spindasis victoriae (Butler)

56 Acraea horta L.

57 Cynthia cardui L.

58 Hypolimnas misippus L.

59 Junonia hierta Fab.

60 Junonia oenone L.

61 Papilio horta L.

62 Belenois thysa Hopffer

63 Catopsilia florella (Fab.)

64 Pieridae sp1

65 Macroglossum trochilus (Hubner)

66 Heterocera sp1

67 Heterocera sp2

68 Heterocera sp3

69 Heterocera sp4
Lygaeidae

Pentatomidae

Tingidae

Apidae

Apidae

Apidae

Braconidae

Braconidae

Chalcidoidea

Formicidae

Halictidae

Halictidae

Halictidae

Megachilidae

Scoliidae

Vespidae

Vespidae

Arctiidae

Arctiidae

Hepialidae

Hesperidae

Hesperidae

Hesperidae

Lycaenidae

Nymphalidae

Nymphalidae

Nymphalidae

Nymphalidae

Nymphalidae

Nymphalidae

Pieridae

Pieridae

Pieridae

Sphingidae

ni

ni

ni

ni
Heteroptera

0.74

0.96

0.39

77.12

Heteroptera

0.14

0.09

0.01

0.02

0.21

0.61

1.86

0.1

Hymenoptera

0.9

Hymenoptera (bw)

$<0.01$

$<0.01$

Hymenoptera (bw)

0.01

$<0.01$

Hymenoptera (bw)

0.14

0.1

Hymenoptera (bw)

$<0.01$

Hymenoptera

$<0.01$

$<0.01$

Hymenoptera (bw)

0.10

0.1

Lepidoptera (mo)

0.11

0.1

Lepidoptera (mo)

0.50

0.5

Lepidoptera (mo)

$<0.01$

$<0.01$

Lepidoptera (but)

0.03

$<0.01$

Lepidoptera (but)

0.17

$<0.01$

Lepidoptera (but)

0.09

Lepidoptera

0.02

Lepidoptera

0.02

$<0.01$

1.12

$<0.01$

Lepidoptera (but)

1.2

Lepidoptera (but)

$<0.01$

$<0.01$

Lepidoptera (but)

$<0.01$

$<0.01$

Lepidoptera

0.01

$<0.01$

$<0.01$

Lepidoptera (but)

$<0.01$

$<0.01$

Lepidoptera

0.11

Lepidoptera

0.42

0.3

Lepidoptera

0.39

Lepidoptera

0.01

Lepidoptera (mo)

0.03

$<0.01$

Lepidoptera (mo) 


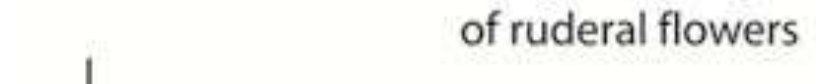

Plor22

Flower visters

Ptants

Phor 20

Hower visitocs

Plants

Plor 18

Flower visions

Punts

10000

flower units
High diversity

of ruderal flowers
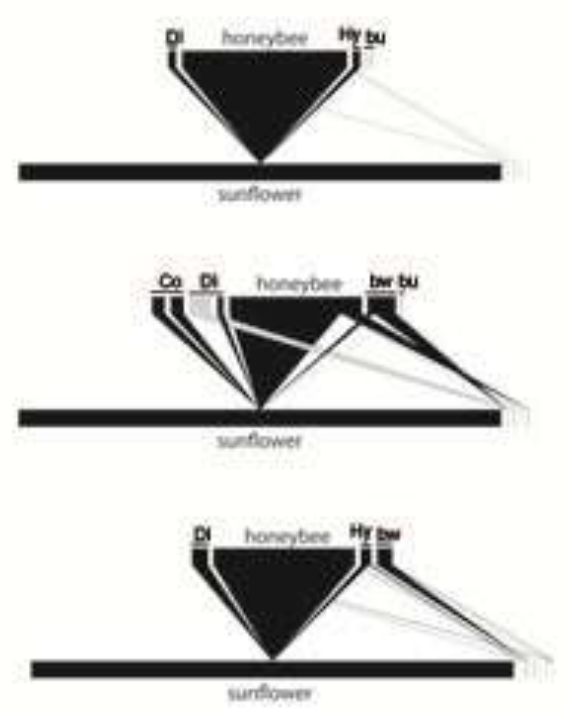

100

flower visitors

\section{Low diversity \\ of ruderal flowers}

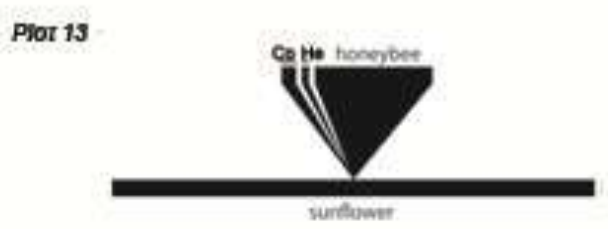

Plor 14

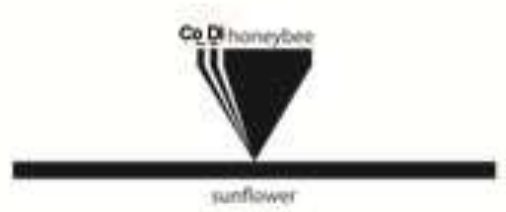

Plor 15

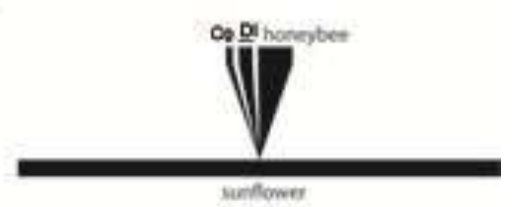

$\mathrm{mb}$ - maize-beetle (0.5-2 x honeybee wingspan; high activity); Co - other Coleoptera, $\mathrm{fl}$ - flies (0.5-2 $\mathrm{x}$ honeybee wingspan; high activity); $\mathrm{Di}$ - other Diptera; $\mathrm{He}$ - Heteroptera; bw - other bees and wasps (0.5-2 $\mathrm{x}$ honeybee wingspan; high activity); $\mathrm{Hy}$ - other Hymenoptera; mo - moths ( $>2 \mathrm{x}$ honeybee wingspan; low activity); but butterflies ( $>2 \times$ honeybee wingspan; high activity).

Figure S1. Effect of distance to managed honeybee colonies and of ruderal plant flowering diversity on sunflower flower visitation webs. The six plots here presented represent two sets of plots located within the same farm and are located far (540-1220m) from natural habitat and near (70-100m), medium distance (490-549m) and far (970-1000m) from introduced honeybee colonies (see plot details in Table S1). Each species of plant and insect is represented by a rectangle. Each species of plant and insect is represented by a rectangle. The list of species is provided in Tables S2 and S3. The widths of the rectangles represent overall species abundance per plot per survey and the size of the lines connecting them represents the number of insects visiting each plant species. Sunflower and its flower visitors are shown in black, while other species are presented in grey. Dashed lines represent rare interactions. 
Pannar 7033

Pannar 7355

Syngenta

Monsanto DK4040
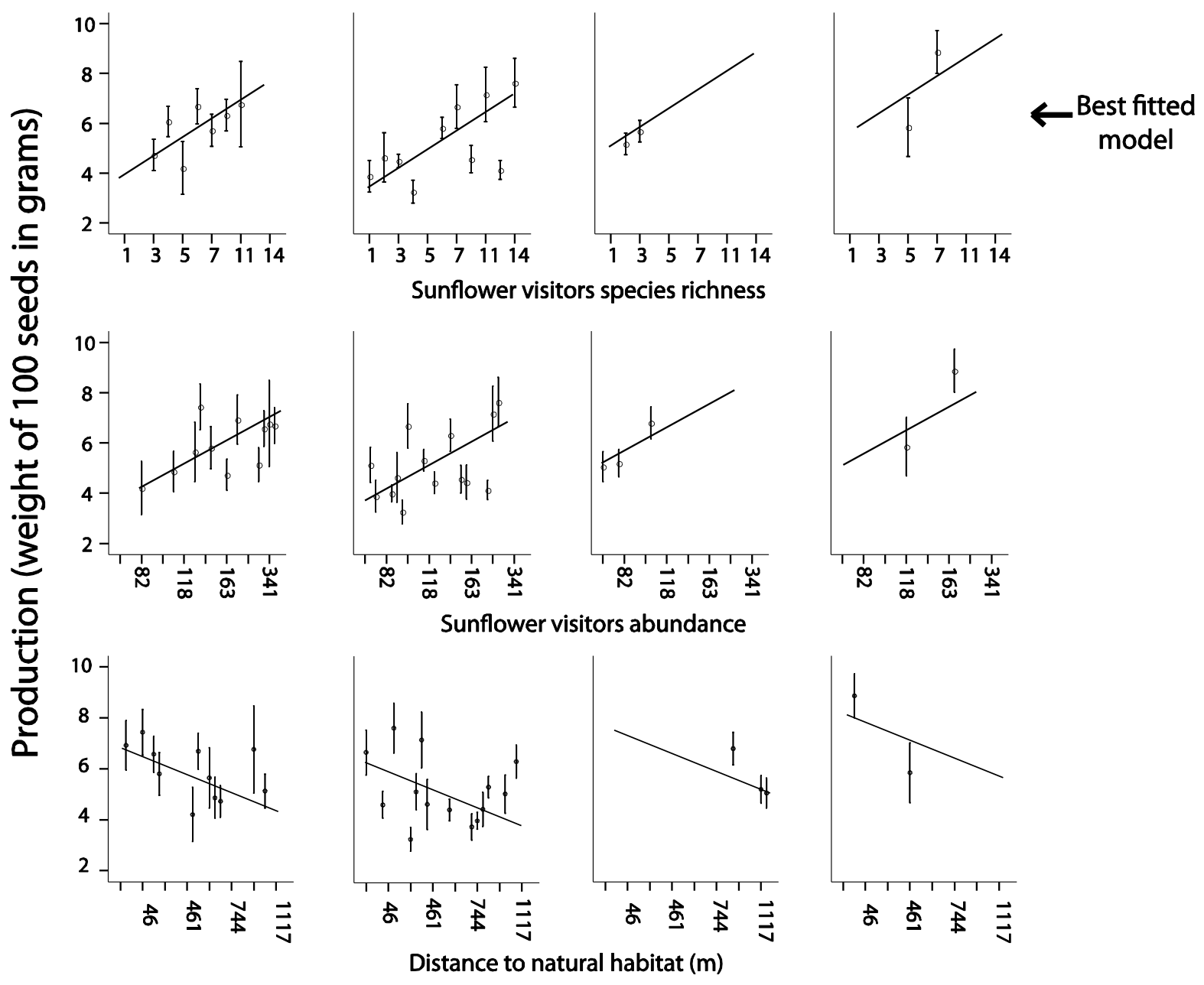

Figure S2. Variation of average sunflower production (whiskers: standard error of production within each plot) with distance to natural habitat, sunflower visitor abundance and species richness for the four main sunflower cultivars used in the study region. Model details are provided in Table 2. Total number of observations: Pannar 7033 - 94; Pannar 7533 - 122; Syngenta - 27; Monsanto DK4040 - 15. 